\title{
Other Architecture and Engineering Workers
}

National Cancer Institute

\section{Source}

National Cancer Institute. Other Architecture and Engineering Workers. NCI Thesaurus.

Code C122534.

Architecture and eng ineering workers not specifically identified elsewhere. 